\title{
The Best Multidigit Computation Methods: A Cross-cultural Cognitive, Empirical, and Mathematical Analysis
}

\author{
Karen C. Fuson \\ School of Education and Social Policy, Northwestern University, United States \\ Received February 10, 2020; Revised March 11, 2020; Accepted March 19, 2020
}

Copyright $\odot 2020$ by authors, all rights reserved. Authors agree that this article remains permanently open access under the terms of the Creative Commons Attribution License 4.0 International License

\begin{abstract}
Many different methods of multidigit computation have been used historically and are now used around the world, but the context in which multidigit computation now occurs has changed. The worldwide availability of electronic calculators has decreased the need for complex computations. The emphasis now can be on understanding methods as well as performing them. This paper outlines a research program conducted over thirty years to find and test multidigit computation methods that are mathematically desirable and that many kinds of students and teachers can understand and explain. A nurturing Math Talk classroom environment, in which students made and explained math drawings supported sense-making by students and teachers. Powerful and simple math drawings were also developed and assessed. The methods and math drawings identified by this research for multidigit adding, subtracting, multiplying, and dividing are described. Examples are given of student explanations with the drawings. The criteria for deciding which methods are mathematically desirable are given, and the methods are judged by these criteria. Some methods that are common in various countries but that are difficult and may stimulate errors are described so that they might be replaced by the best methods identified by this research. How these methods fit the math standards of two different countries, the United States and China, is described. Sense-making about and using the identified best methods can reduce errors and engender understanding.
\end{abstract}

Keywords Place Value, Multidigit Computation, Multidigit Addition, Multidigit Subtraction, Multidigit Multiplication, Multidigit Division, Meaningful Computation, Standard Algorithms

\section{Introduction}

Many different methods of multidigit computation have been used historically and are now used around the world [1-7]. These methods vary in their complexity, generalizability, and the ease with which they can be understood and explained. For centuries the emphasis was on rapid and accurate computation without any need to understand the method being used. The widespread availability of calculators in the past decades changed the need for human calculators from just producing answers to understanding a method so it might be modified if needed in the future. There was also an increasing emphasis around the world on students and teachers understanding mathematics and on students inventing and sharing their methods.

These changing contexts for computation led me to these research questions:

1. Are there multidigit computation methods that are mathematically desirable and accessible to many kinds of students and teachers?

2. Can teachers understand and explain these methods?

3. Can students understand and explain these methods?

This paper addresses these questions by outlining the steps taken to address these research questions and then describing the methods identified by this process along with complexities found for each method. The results focus on two mathematically desirable and accessible methods for each kind of multidigit computation (addition, subtraction, multiplication, division). These methods are contrasted with methods considered "the standard algorithm" and taught in most textbooks in the United States. Some common methods used in other countries are identified and compared in this paper or discussed in references. The results recommend particular methods for inclusion in mathematics programs around the world and 
criteria for the selection of these methods.

Our theoretical framework uses both a Piagetian constructivist model of learning and a Vygotskian socio-cultural model of teaching $[8,9]$. From our Piagetian perspective, we assume that students are continually interpreting their classroom experiences using their own conceptual structures as well as continually adapting their conceptual structures to their on-going classroom experiences. From our Vygotskian perspective, we assume that a major goal of school mathematics teaching is to assist learners in coming to understand and use cultural mathematics tools. One powerful means of teaching/learning assistance is math drawings, which are semiotic tools that can support sense-making both individually and in the classroom discourse about mathematical thinking. Therefore, our teaching approaches primarily used math drawings that teachers and students could make and explain. A nurturing Math Talk classroom environment supported sense-making by students and teachers [9].

\section{Materials and Methods}

Thirty years of coordinated research efforts addressing the above research questions are briefly overviewed here. References allow readers to understand more details of these efforts; many of these references are available here [10]. The two multidigit methods for each operation identified as worthy of inclusion in mathematics programs around the world are described in the Results section along with criteria for their choice and research-based approaches to teaching these methods for understanding. This allows the reader to focus there on the final results of these decades of research and to relate these methods to each other.

\subsection{Data Collection Methods}

Step 1: Gather and analyze multidigit computation
methods:
Multidigit computation methods were identified in the
following kinds of sources:
a. methods used around the world historically [7]
b. textbooks from African, Asian, European, and North
and South American countries;
c. research articles and summaries [1-6];
d. conversations with colleagues and students at
national and international conferences.

These methods were analyzed for their mathematical similarities and differences. Attention was given to the language spoken by students and how this language might interact with the method. Methods that were mathematically desirable and seemed accessible to students were identified.

Step 2: Gather methods students invent and explain in supportive meaning-making learning situations and develop and assess teaching supports for computation methods identified in Step 1 and/or invented by students:

The author and Children's Math Worlds Project researchers carried out exploratory studies with small groups of students and with whole classes in the United States. Initial studies focused on multidigit addition and subtraction. Six small groups of second graders used base-ten blocks to model and solve 4-digit addition and subtraction problems. Students had not yet learned any methods for multidigit addition or subtraction in school. Groups were videotaped, and the large pieces of paper on which students recorded their written methods were collected. These written methods recorded things students did with the blocks on the large 3-row 4-column place-value sheet. Seven correct addition methods and sixteen correct subtraction methods were identified [11]. Several of these had advantages over the methods taught in schools in the United States. Seven incorrect addition methods and sixteen incorrect subtraction methods were also identified. Some of these were corrected by the students to form a correct method.

Teaching studies were then carried out in four urban classrooms to teach the best addition and best subtraction methods invented by students. In one first-grade and one second-grade classroom students used base-ten blocks to show steps in adding and subtracting and recorded methods on big sheets of paper. In another first-grade and another second-grade classroom students used a much less expensive version: blocks cut from felt by parent volunteers (thousands were 10 hundreds blocks clipped together). Many students did learn the methods chosen as the best of the invented methods. However, there were two major problems in the whole-class situation. First, students could not see the blocks when students explained their methods so there were no visual quantity supports for the written method being explained. Second, all of the materials were lost over the summer in the large urban school.

For these reasons we moved in the following year to drawings students made for ones, tens, and hundreds. First graders drew tens and ones and used these to show 2-digit addition and subtraction problems [12,13]. Second graders drew hundreds, tens, and ones to show 3-digit addition and subtraction problems [14]. The author and project staff observed and co-taught in these classrooms. Methods invented by students were also recorded. A major focus in these studies and in those in Step 3 was to identify how students could learn to make place-value drawings meaningfully and rapidly. Students drew columns of ten dots and then drew a line through the dots to make a ten-stick. Eventually the ten-sticks were called fast tens and only the stick was drawn, though the ten dots could be imagined and drawn as needed. The math drawings students made supported explaining to the whole class, 
most students could carry out addition and subtraction accurately, and many students could explain their method. Performance was substantially higher than for students of these teachers in earlier years.

The initial multidigit multiplication and division studies were done later than those for addition and subtraction, but they followed the same general approach of working with small groups and with whole classes. This computation was modeled by area drawings initially given to and later made by teachers and students. An initial phase of students inventing methods was not productive because students used different kinds of non-ten groupings for different problems and so did not develop any general methods. We then wrote materials to support teachers to connect area model drawings to written multidigit methods using place values, and especially to a method invented by urban fourth graders who wrote out all four partial products with their factors and recorded the largest first to make it easy to align subsequent smaller partial products. Fourth graders learning with these materials in one urban and one suburban classroom outperformed fifth graders using a traditional curriculum in the United States and were equivalent to Japanese and Chinese fifth graders $[15,16]$. A subsequent study with fifth graders identified difficulties students can have differentiating arrays of dots from areas made from square units especially if earlier grade levels used only arrays of dots $[17,18]$. Therefore, for Step 3 below we developed a coherent sequence of emphasizing and differentiating dot arrays and areas with square units for single-digit multiplication and used area models in Grades 4 and 5 to support these more difficult concepts [19].

For division we used in two urban fifth grade classrooms vertical area model drawings that paralleled an accessible written division method in which students could accumulate quotients (the number of divisors) out to the right of the dividend [20,21]. This allowed students to underestimate and still keep accumulating quotients. Teachers reported that students were more accurate in division than they had been with other approaches, but we felt that this method allowed students to build answers too slowly and did not relate sufficiently to their representations for multiplication. Therefore, we moved in Step 3 to using the same area model as for multidigit multiplication and helped students to build up partial quotients in the area model and record these in the written division method. This method did allow students to underestimate and keep adding partial quotients, but they did this much less than they had done with the earlier vertical model.

Step 3: Address the three research questions by writing, assessing teachers teaching, and revising written units focused on multidigit computation and using large whiteboards with supports for student drawings.

\subsection{Participants}

For multidigit addition and subtraction, participants were Grade 1 through Grade 4 students in classrooms participating in the Children's Math Worlds research project. We gathered data for three years from six classrooms of students at Grades 1 and 2, with one classroom at each grade level in each of three urban schools. Classes ranged in size from 20 to 28 . We gathered data for three years from four classrooms of students at Grades 3 and 4, with one classroom at each grade level in one urban school and in one suburban school with many immigrants. Classes ranged in size from 26 to 37. Across these classrooms a large minority of the students were on free lunch (an index of low family income). Close to half the students were from Spanish-speaking backgrounds, and another third used a variety of other languages at home. This diversity was chosen to test the accessibility of our approaches to a broad range of students and to ascertain what multidigit computation methods students brought from their homes. Teaching materials were in English, and the bilingual teachers in the not-yet-English-fluent classrooms taught in English supplemented as needed with Spanish or other languages.

For multidigit multiplication and division, in each of two urban schools we gathered data for two years from two classrooms of students at Grade 4 and two classrooms at Grade 5. Classes ranged in size from 28 to 38. The backgrounds of students were similar to that of the students described above.

\subsection{Teachers and Teaching Materials}

The author and research staff of the Children's Math Worlds research project wrote units on multidigit addition, subtraction, multiplication, and division. Multidigit addition and subtraction with regrouping were taught in Grades 1 through 4, with totals increasing from 100 in Grade 1 to 1000 in Grade 2 to 2000 in Grade 3 and to $1,000,000$ in Grade 4. Multidigit multiplication and division were taught in Grades 4 and 5, moving from 1x3-digit, 1x4-digit, and 2-digit x 2-digit in Grade 4 to 3-digit $x$ 3-digit in Grade 5. The regular classroom teachers taught these units with occasional teaching support from research project staff if requested.

The author and project research staff observed classrooms, took notes, interviewed students and teachers, and collected quizzes and unit tests to analyze errors. The author talked by phone with teachers to answer any questions about the teaching and to discuss how the student learning was going. A major focus was on students making drawings for the computations, relating their drawings to steps in their computations, and explaining their written method. Materials were revised each year in response to the teacher and student data to improve learning and make the units easier to teach. 
All grade levels used special large (11 3/4 inches by 17 inches; $30 \mathrm{~cm}$ by $43 \mathrm{~cm}$ ) student dry-erase boards with grade-level learning supports to help students learn to make multidigit drawings rapidly and meaningfully and to have room to make math drawings and written methods. The Grade 1 and Grade 2 dry-erase boards had two adjacent 10 by 10 arrays of dots 1 centimeter apart. Students drew down each column to make ten-sticks and counted these ten-sticks by tens $(10,20,30$, etc.). They drew a square around an array of ten ten-sticks to make a hundred-box that could be seen as ten ten-sticks or as 100 dots. They soon began making sketches to show numbers as composed of hundred-boxes, ten-sticks, and ones. The Grade 3 dry-erase whiteboard had an array of 24 by 40 dots $1 \mathrm{~cm}$ apart to permit drawing hundred-boxes, ten-sticks, and ones. To help guide discussion that differentiated dot arrays from arrays of unit squares made by joining adjacent dots, this board had small circles between every group of five dots along one short side and one adjacent long side. The other short and long side had small + signs beside each row or column of five dots. Students turned the board so that the desired units (dots or drawn unit lengths to make squares) were on the left side and top. The Grade 4 dry-erase board had an array of 50 by 100 dots $4 \mathrm{~mm}$ apart. The same small circles or + marks were used every 10 units to differentiate dot arrays from arrays made of drawn unit squares (an area model). For other visual supports for place-value and counting that were on the whiteboards see [22].

Our research data indicated that the two methods for each kind of multidigit computation to be described below in the Results section were accessible to teachers and to students. Most students could make drawings for and do accurately at least one multidigit method. Many students could explain at least one method and at least a third of most classes could explain two methods. This performance was considerably above that for classes of these teachers in earlier years. These methods and approaches were therefore used in a mathematics program written by the author and published by a major publisher Houghton Mifflin Harcourt [23].

Step 4: Compare the identified methods, teaching supports, and standards to those in the high-achieving East Asian countries China, Japan, and Korea; clarify the confusions in the term "the standard algorithm"; and articulate and use criteria for mathematically-desirable and accessible multidigit computation methods.

During Step 3 an ambitious national effort in the United States was undertaken to agree on grade-level standards common to all states. Up to this point each of the 50 states had their own standards, with variations by as much as three years across states. Thus large amounts of time were spent on what to teach and on taking apart math programs to fit standards of a particular state. This left little time to focus on how to improve teaching. The new Common Core State Standards focused on understanding and on fluency [24] and had approaches and grade-level multidigit computation topics consistent with the research in Step 3.

However, there were many confusions about the meaning of the words strategies, algorithms, and "the standard algorithm" that were used in the Common Core State Standards. Many educators took the word strategies to mean "student invented" and algorithms to be bad and to be delayed or avoided because historically algorithms were frequently taught without understanding. The term "the standard algorithm" was particularly difficult because this was interpreted as "the method I learned in school" or "the method in my current math program." These methods varied, and they were often not easy to understand or explain or teach with any understanding. So some educators were spending a lot of time on student strategies that did not generalize to all numbers or to larger place values although the Common Core State Standards emphasized generalizable methods of multidigit computation. Other educators were teaching traditional methods that resulted in many errors. Teachers and math programs were using many different methods with no criteria for mathematical desirability or accessibility of the methods.

To clarify meanings of these words in the Common Core State Standards, Fuson and Beckmann clarified the meaning of the disputed vocabulary, developed criteria for mathematical desirability of written methods, and described the two methods for each multidigit computation that had been supported by the research in Steps 1, 2, and 3 [25]. These are all described in the Results section below. Although the method most frequently used in a country may vary across countries, the tendency not to question that current common method occurs in different countries. So using a mathematical definition of the desirability of methods, such as we outline in the Results section, can be of value in various countries in judging the desirability of the method commonly used at that time.

To assess the generalizability of the identified methods across high-achieving countries, Fuson and Li [3] analyzed methods used and textbook supports for multidigit addition and subtraction in China, Japan, and Korea. This was compared to methods and textbook supports in the Math Expressions program developed in Step 3. Fuson and Li [26] examined math standards in China and the United States to assess their support of the identified mathematically-desirable and accessible methods.

The consensus methods revealed by the research in Steps 1 through 4 are discussed next along with the visual and linguistic teaching supports used to support student and teacher understanding and explaining these methods. 
Criteria for mathematically desirable methods are summarized and used to evaluate various methods.

\section{Results}

\subsection{What Is "the Standard Algorithm"?}

Because there are many different algorithms used over time and in different countries, no one method can be "the standard algorithm". Fuson and Beckmann [25] analyzed documents and dialogue about this issue and concluded that these sources together indicate "that the standard algorithm for an operation implements the following mathematical approach with minor variations in how the algorithm is written:

- decomposing numbers into base-ten units and then carrying out single-digit computations with those units using the place values to direct the place value of the resulting number; and

- using the one-to-ten uniformity of the base ten structure of the number system to generalize to larger whole numbers and to decimals." (p. 15)

This definition highlights the importance of students knowing accurate and rapid enough single-digit methods of adding, subtracting, multiplying, and dividing. How learning these with understanding can support accurate multidigit methods will be discussed for each operation below. The definition above also clarifies that base-ten place-value must be understood and supported for meaningful multidigit methods. Useful place-value approaches will also be discussed for each operation.

In the past in the United States and in many other countries, teaching "the standard algorithm" has too often meant teaching numerical steps by the teacher demonstrating them and having students memorize the steps rather than understand and explain them. The Common Core State Standards [24] clearly do not mean for this to happen. Students begin by making sense of and explaining a multidigit computation method. In the initial grade in which a multidigit computation is introduced, the standards specify that students are to

- $\quad$ use concrete models or drawings and_strategies based on place value, properties of operations, and/or the relationship between addition and subtraction; relate the strategy to a written method and explain the reasoning used. [Grade 1 addition 1.NBT.4 and Grade 2 addition and subtraction 2.NBT.7 and 9],

- illustrate and explain the calculation by using equations, rectangular arrays, and/or area models. [Grade 4 multiplication and division 4.NBT.5 and 6].

However, the Common Core State Standards also specify in the critical areas on the first page for these grade levels that students are to "develop, discuss, and use efficient, accurate, and generalizable methods" for adding/subtracting (Grades 1 and 2) and for multiplying/dividing (Grade 4). So from the very beginning grade for a kind of multidigit computation teachers need to help students make sense of and explain written computation methods that may be elicited from students but also ensure that students develop, discuss, and use efficient, accurate, and generalizable methods.

\subsection{Multidigit Addition}

\subsubsection{The Best Method}

To do the necessary sense-making and explaining, students need experience with place-value concepts that includes being able to use visual representations of place-value quantities (e.g., hundreds, tens, and ones) to support carrying out and explaining their written method. We show in Figure 1 a Grade 2 student explaining using drawings of ones, tens, and hundreds the method identified as the best written version of the standard addition algorithm in the Fuson and Beckmann [25] and Fuson and Li [26] papers. This method was also identified as an accessible and generalizable method in the National Research Council Report Adding It Up [5] and in the NCTM Research Companion to Principles and Standards for School Mathematics [20]. As outlined in Step 3 above, the quantities in the drawings can be built up meaningfully by having students draw line segments through vertical columns of ten dots. Ten such vertical columns can be boxed to make 100 (100 ones and ten tens at the same time). Students draw to show various 2-digit and then 3-digit quantities.

Figure 1 shows how relating each step of the written method to the drawing and explaining that step using place-value language enables listeners to understand the explainer. Following such a student explanation by questions from other students as shown in the bottom of Figure 1 supports sense-making by the whole class because they can be invested in listening closely so they can ask questions they have or questions to help classmates understand an important point.

Notice also how the drawings support learning more-advanced single-digit addition methods when numbers are drawn using groups of 5. For example, one can see that 9 needs 1 more to make ten and that 1 is taken from the 7 to leave 6 . So $9+7=10+6$, which is easy if students understand teen numbers as 1 ten and some ones. This method then can be done mentally, as indicated by Jorge's question. Such make-a-ten methods are taught in East Asia [27 - 31] but have not been taught frequently in the United States before the Children's Math Worlds Project began doing so as early as Step 2 above. Such methods are abbreviations of the experientially earlier two levels of solution methods: 1) counting all of the objects and 2) counting on from one addend, such as counting on seven from nine: nine, ten, eleven, twelve, thirteen, fourteen, fifteen, sixteen [32,5]. The three levels of counting all, counting on, and make-a-ten methods can be 
done for larger units such as tens, as the explainer did in step c. The make-a-ten methods are now more commonly taught in the United States because these methods are explicitly in the Common Core State Standards (1.OA.6) and the three prerequisite understandings for the make-a-ten methods are standards in Kindergarten (K.OA.3 and 4, K. NBT.1); see [33] for kindergarten children enacting these prerequisite understandings.

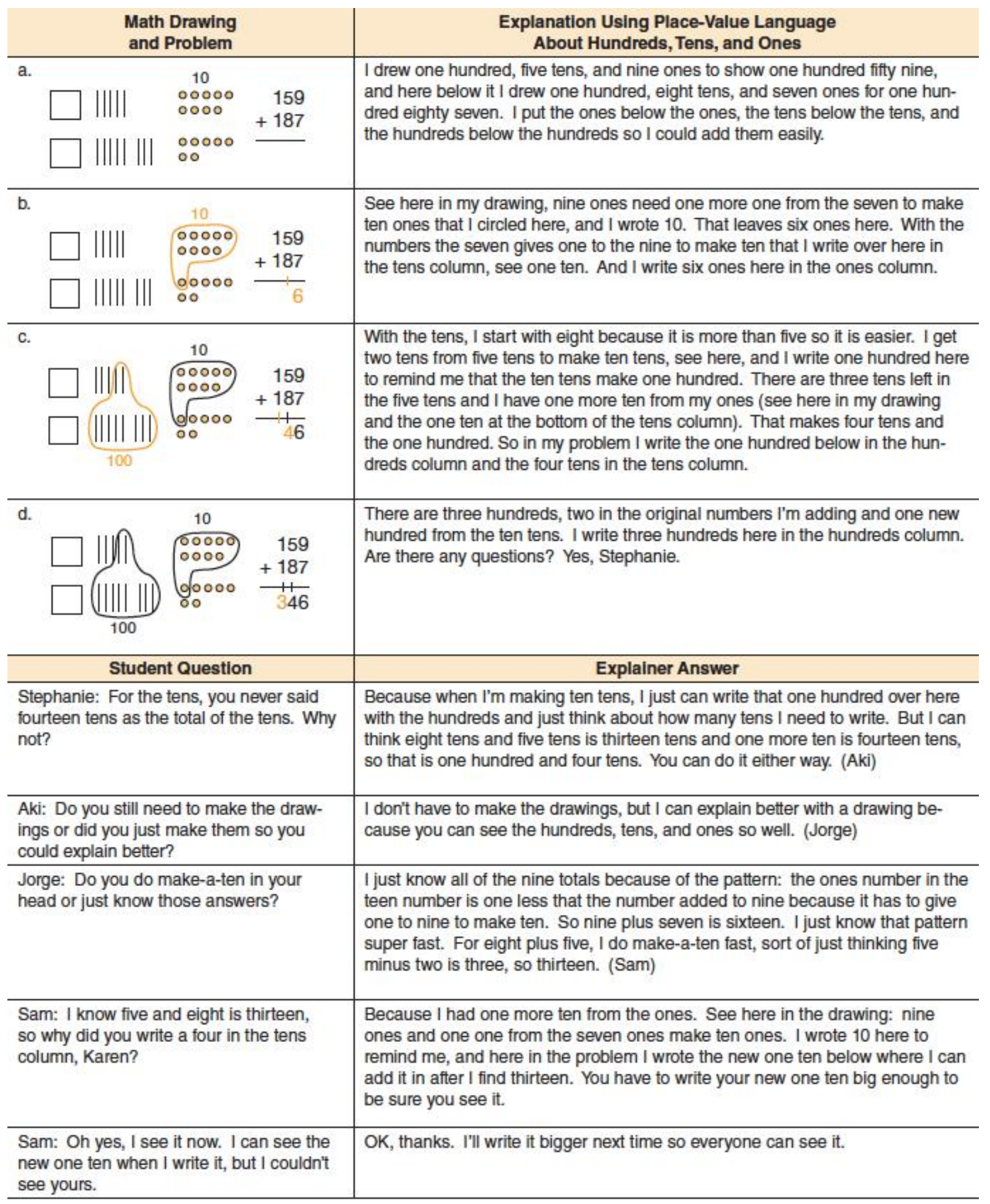

Figure 1. Grade 2 related explanation, drawing of quantities, written method, and questions for the New-Groups-Below Method for adding

3.2.2. Variations of Written Methods That Decompose the Place Values and Criteria for Mathematically Desirable Written Methods to Introduce in the Classroom

Figure 2 below shows four variations of written methods that decompose the place values--the hundreds, tens, and 
ones. The drawings at the top of Figure 2 can be used to explain any of the methods for 3-digit numbers. Methods E, F, and $\mathrm{G}$ generalize easily to larger numbers; each is shown at the bottom of Figure 2 for 6-digit numbers. These methods have small variations in where and how the new one ten and new one hundred are written. Their similarities underscore how important it is to have mathematical criteria for which method is better. Such criteria are shown in Table 1 .

\section{Place value drawing for all methods}

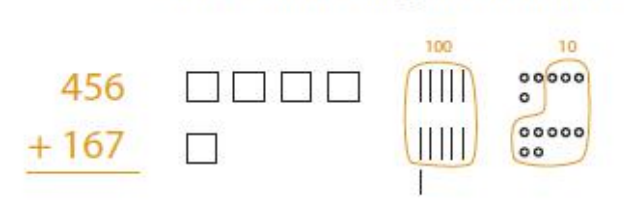

General methods for 2- and 3-digit numbers

\begin{tabular}{rrrr} 
D. 456 & E. 456 & F. $\stackrel{56}{456}$ & G. 456 \\
+167 & +167 & & +167 \\
\hline 500 & $\begin{array}{r}167 \\
110\end{array}$ & & +167 \\
\hline 13 & & & 623 \\
\hline 623 & & &
\end{tabular}

Methods $E$, F, and G generalized to 6-digit numbers

\begin{tabular}{|c|c|c|}
\hline E. 456,789 & 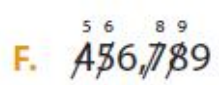 & G. $\quad{ }^{\prime}{ }^{\prime} 56,7{ }^{\prime}{ }^{\prime}$ \\
\hline$+167,189$ & $+167,189$ & $+167,189$ \\
\hline 623,978 & 623,978 & 623,978 \\
\hline
\end{tabular}

Figure 2. Multidigit addition methods that decompose into base ten units

Table 1 shows the criteria identified by Fuson and Beckmann [25] and Fuson and Li [26] as important to choose the best methods to be taught in the classroom. This table combines features of both papers, which vary in specificity. No methods met all criteria, but one addition and one subtraction method met more criteria than other methods. Table 2 uses these criteria to analyze Methods $\mathrm{E}$ and $\mathrm{G}$ in Figure 2. Method $\mathrm{G}$ is the current common method in the United States, but it has several disadvantages compared to the new Method E.

Table 1. Criteria for Emphasized Written Methods That Should be Introduced in the Classroom

\begin{tabular}{|l|l|}
\hline 1. Variations that support and use place value correctly because understanding and using place value is crucial: \\
\hline a. Adding/subtracting like quantities is made easier by aligning like places (units). \\
\hline b. It is easy to see the teen total for the new grouped or ungrouped unit. \\
\hline c. It is easy to see where to write the new unit. \\
\hline 2. Variations that make single-digit computations easier, given the centrality of single-digit computations in algorithms. \\
\hline 3. $\quad$ Variations that allow children to write teen numbers in their usual order (e.g., for 14 write the 1 and then the 4 ). \\
\hline 4. Variations in which all of one kind of step is done first and then the other kind of step is done rather than alternating, because \\
\hline 5. Variations that keep the initial multidigit numbers unchanged because they are conceptually clearer. \\
\hline 6. Variations that can be done left to right are helpful to many students because many students prefer to calculate from left to right. \\
\hline
\end{tabular}

Note. This table is adapted from and combines elements of related tables in Fuson and Beckmann [25] and Fuson and Li [26]. 
Table 2. Criteria Met by the New-Groups-Below Method E and Not Met by the New-Groups-Above Method G

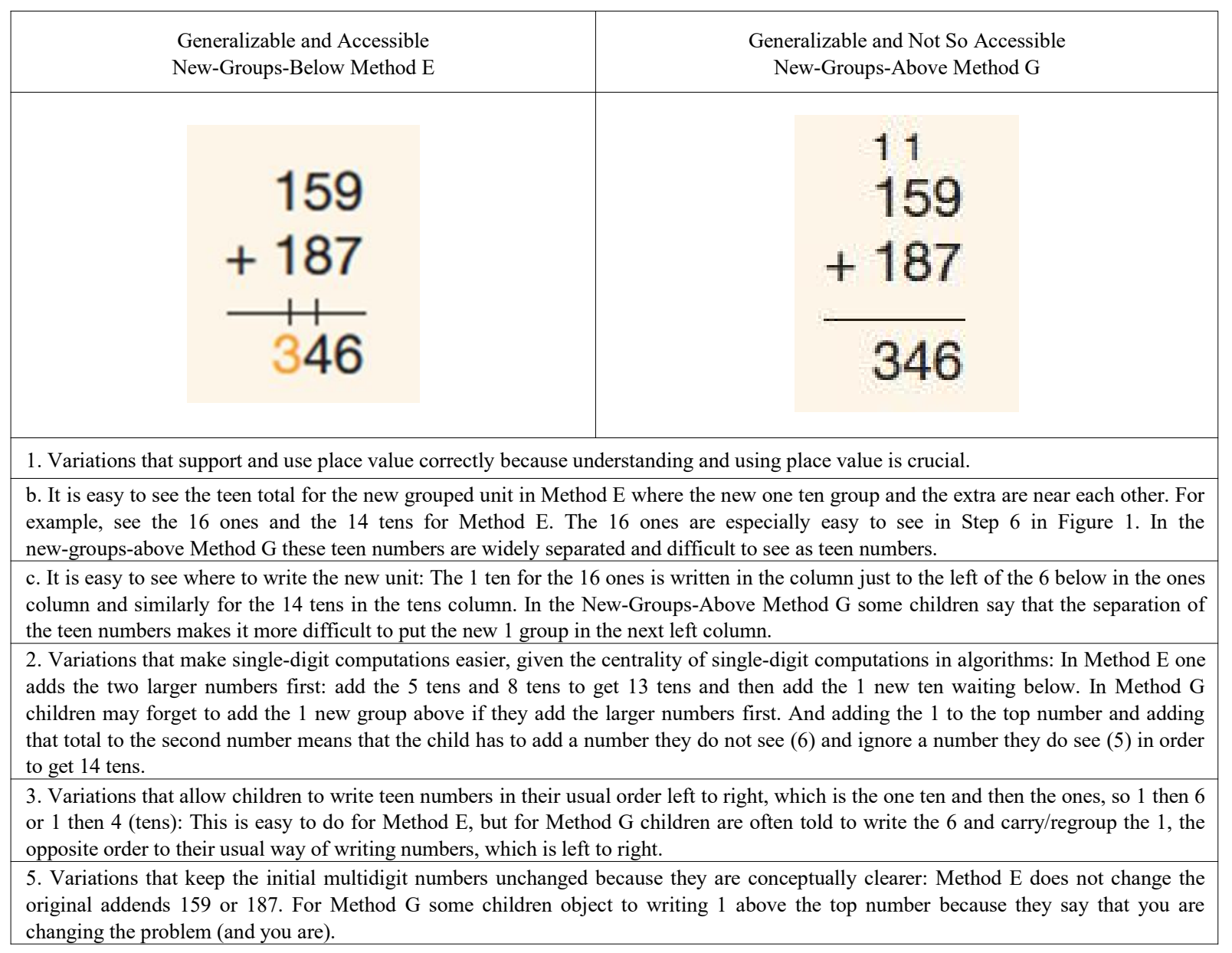

Method D in Figure 2 also scores high on the criteria in Table 1, but Method D becomes cumbersome for large numbers. Therefore we call it a Helping Step Method that shows with expanded notation how students are adding digits in a column with the same place values. Some students find it helpful to see the place values with the zeroes that hold the values in their places. Place value is a more difficult conceptual construction for students speaking English where the tens are not explicitly named as tens than for East Asian or other children who say ten six for 16 and one hundred five ten for 150. For this reason Math Expressions uses the layered place-value cards shown in Figure 3 where the single-digit place values on the left $(346)$ can be seen as the place values 3 hundreds 4 tens 6 ones when the cards are moved apart as shown on the right. The backs of these cards show the number of hundreds, tens, and ones as in the drawings used in Figure 1 (3 hundred-boxes, 4 ten-sticks, 6 ones circles). The Helping Step Method can be done from the left or from the right, which supports productive discussions and helps students who prefer to operate from the left. Students can also use regular base-ten words to describe numbers as well as English words. So they might say 5 tens plus 8 tens is 13 tens or fifty plus eighty is one hundred thirty.

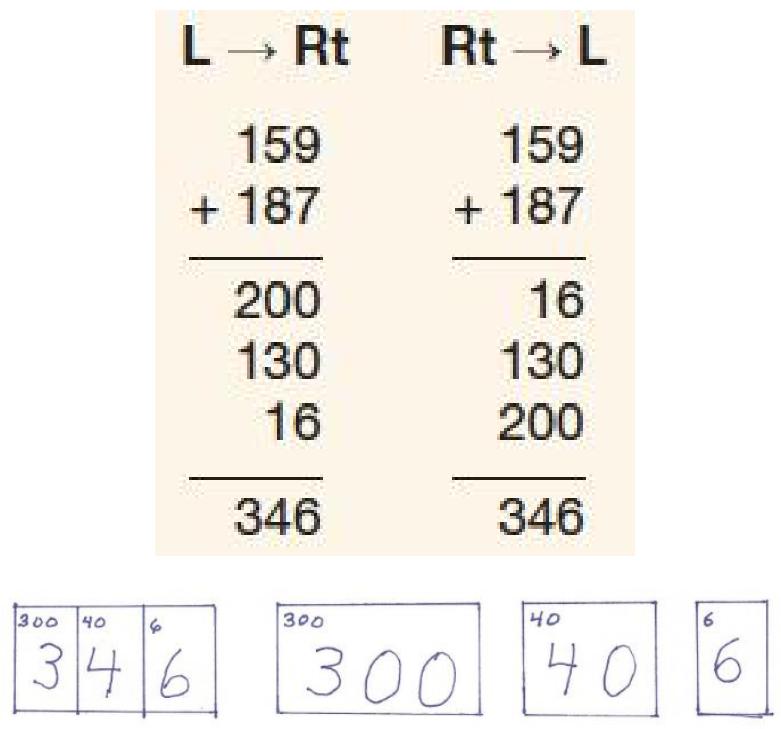

Figure 3. Helping Step Expanded Notation Methods and Layered Place-Value Cards to show meanings of places

There are also methods that begin with one whole number and count on or add on the other number $[25,32]$. 
But these become difficult even for three digits because the counting on by hundreds, tens, and ones is difficult. These methods do not generalize easily for larger numbers, so a generalizable method needs to be introduced and discussed at each grade.

\subsection{Multidigit Subtraction}

The major task for teaching multidigit subtraction is how to help students avoid the very common error of subtracting the smaller from the larger number within a column even if the smaller number is on the top. Even when students know not to do this, a method widely used in the United States seduces students into making this error. In Figure 4 we see the common error at the top. Below is shown the alternating steps in a common way to write multidigit subtraction: Ungroup a column, subtract that column, ungroup the next left column, subtract that column, etc. Look at the second step to see how this method sets students up to make the common error: They have just subtracted the ones column 16-9 and written 7 . They move to the tens column and see a 3 on the top and 5 below. They are in "subtract mode" and their brains rapidly produce 2 as the answer, so they write a 2 .

Common Error: Subtract Within a Column the Smaller Number from the Larger Number

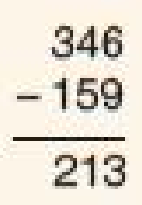

The Generalizable but Not So Accessible Alternating Current Common Method

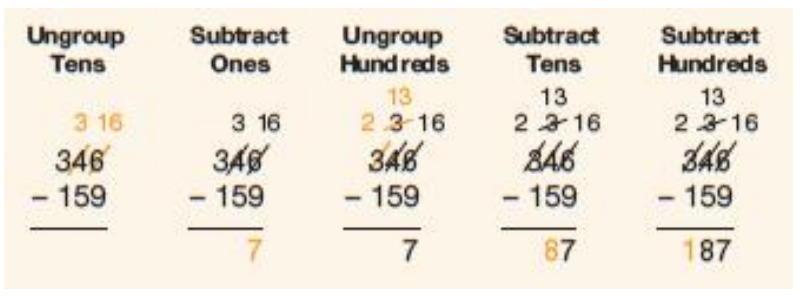

Figure 4. The common error and how a common method seduces students to make that error.

In contrast we show in Figure 5 a Grade 2 student explaining using drawings of ones, tens, and hundreds the method identified as the best written version of the standard subtracting algorithm in the Fuson and Beckmann [25] and Fuson and Li [26] papers. This method was also identified as an accessible and generalizable method in Adding It Up [5] and in the NCTM Research Companion to Principles and Standards for School Mathematics [20]. In this method all of the ungrouping is done first, and then all of the subtracting is done. This is much easier for students than alternating these steps, and it avoids the common error intruding in the middle of the alternating method as shown in Figure 4. This Do-Necessary-Ungrouping-First Method also makes it possible for students to solve from the left, which many students prefer. They can ungroup from the left as shown in Figure 5, and they can also subtract from the left after they have ungrouped where needed to make every top number larger than the bottom. But they can also ungroup from the right and subtract from the right. Students have great conversations about why they can ungroup and subtract in either direction with this method. One of our inner-city classes refused to go out to recess because they wanted to resolve this issue to everyone's satisfaction. Doing all necessary ungrouping first also allows everyone to understand the main conceptual point of subtracting: You have to rewrite the larger number in a form that allows you to subtract in every column. And doing this first allows everyone to double check that all of the top numbers are equal to or bigger than the bottom number before one begins subtracting.

In Step a, we see another visual support that can be used to inhibit the top-from-bottom error from the beginning: Students draw a big loop with a stick to show their "magnifying glass" that lets them "look inside" that whole bigger top number to see if it is ready to subtract in every column. All of the ungrouping is written inside that loop, creating a conceptual focus on that top number in its original and final written versions. This facilitates discussion of whether ungrouping changes the total quantity of the top number (it does not). Drawing the magnifying glass helps students shift from a focus on the vertical columns and subtracting the smaller number in a column to a horizontal focus on the whole number that may need to be ungrouped in order to subtract. So drawing the magnifying glass helps inhibit students from making the common subtract smaller top from larger bottom number. This helping step of drawing the circle and stick can be dropped when a student no longer needs it. 


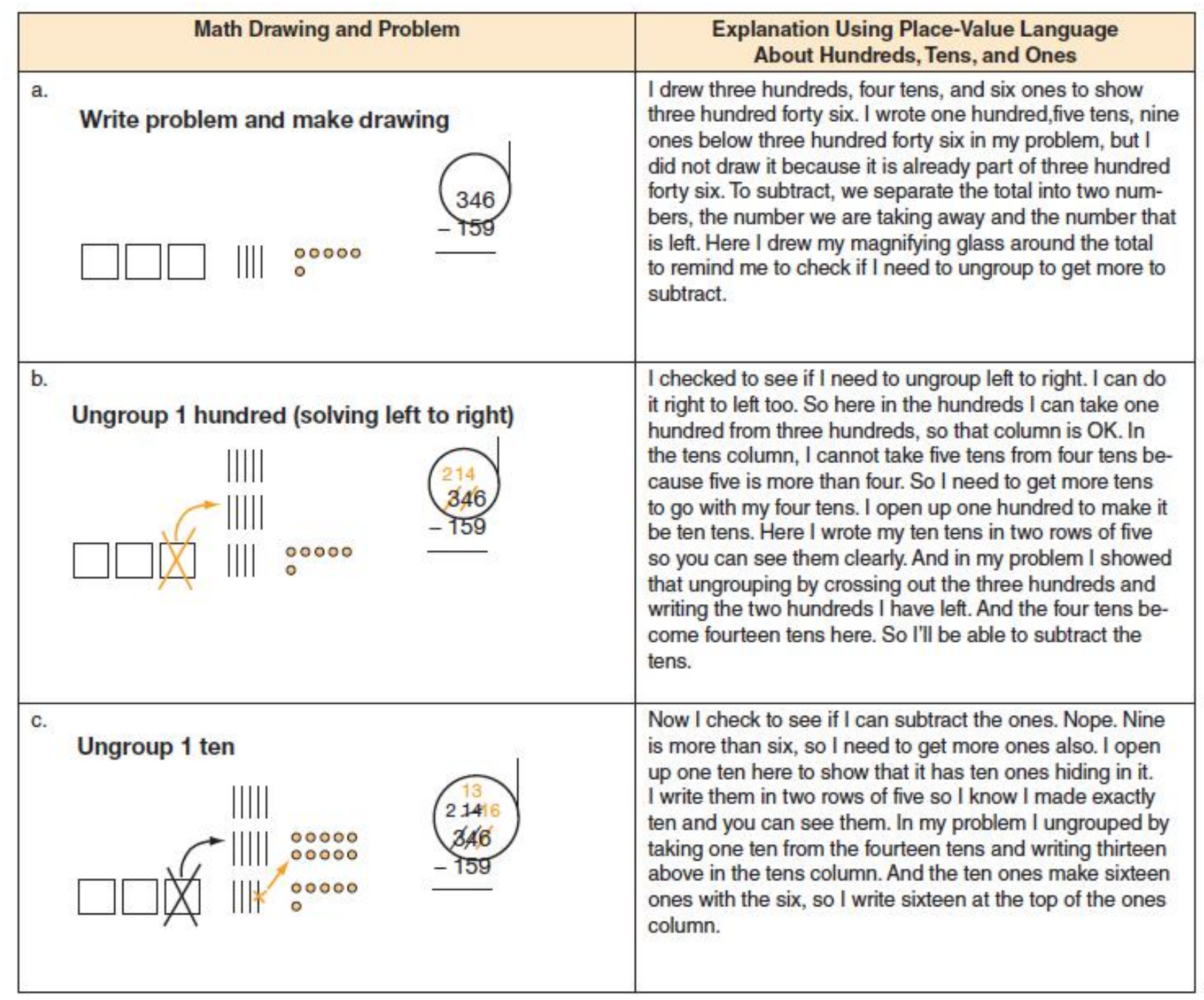

Figure 5a. Grade 2 related explanation, drawing of quantities, written method, and questions for Do-Necessary-Ungrouping-First Method Part I 


\begin{tabular}{|c|c|}
\hline Math Drawing and Problem & $\begin{array}{l}\text { Explanation Using Place-Value Language } \\
\text { About Hundreds, Tens, and Ones }\end{array}$ \\
\hline $\begin{array}{l}\text { Subtract H, T, O } \\
\text { L to Rt or Rt to L }\end{array}$ & $\begin{array}{l}\text { Now I can subtract in every column. I can go in either direction. I'll } \\
\text { go left to right again. I take away one hundred in my drawing, and } \\
\text { one hundred is left. My problem agrees: I take away one hundred } \\
\text { from the two hundreds and write the one hundred that is left. I'll } \\
\text { subtract five tens from thirteen tens and get eight tens. I just know } \\
\text { that. But here in my drawing I'll take the five tens from the ten } \\
\text { tens, and I can do make-a-ten if I don't know thirteen minus five. } \\
\text { See, five more left in the ten and the three in thirteen make eight. } \\
\text { For the ones I can use Karen's pattern she just explained, that the } \\
\text { teen total is one less than the ones added on to a nine. So sixteen } \\
\text { minus nine is seven. See here in the drawing, you can see the } \\
\text { one extra with the nine that gets added to the six ones to make } \\
\text { seven ones. Are there any questions? Yes, Sybilla? }\end{array}$ \\
\hline Student Question & Explainer Answer \\
\hline $\begin{array}{l}\text { Sybilla: Doug, why didn't you subtract six ones from nine } \\
\text { ones to get three ones in the answer? }\end{array}$ & $\begin{array}{l}\text { Because we have to subtract the addend from the total. Six is part } \\
\text { of the total, so we have to subtract from it. But we can't, so that's } \\
\text { why I had to get more ones here. Good question, even though I } \\
\text { know you know this. Hank? }\end{array}$ \\
\hline $\begin{array}{l}\text { Hank: What if you checked your hundreds and the bot- } \\
\text { tom number was bigger? How could you subtract? }\end{array}$ & $\begin{array}{l}\text { I couldn't. The total has to be bigger than the addend I subtract } \\
\text { because that addend is just part of the total. But sometimes I } \\
\text { write the numbers backwards, so I check the problem again if I } \\
\text { can't subtract the hundreds. Efrain? }\end{array}$ \\
\hline $\begin{array}{l}\text { Efrain: How would your problem be different if you had } \\
\text { ungrouped right to left? }\end{array}$ & $\begin{array}{l}\text { Only the tens place would look different. Remember how we did it } \\
\text { both ways and talked about this yesterday? And look at Yeping's } \\
\text { problem. He ungrouped right to left. The tens place looks different } \\
\text { because you ungroup one ten to make ten ones before you } \\
\text { get ten tens. So you write three and then thirteen. But I end up } \\
\text { with thirteen, so the ungrouping gets the same number in each } \\
\text { column ready to subtract. }\end{array}$ \\
\hline
\end{tabular}

The explainer stands to the side and points with a pointer to parts of the math drawing or to parts of the problem as they are mentioned. Pointing is a crucial part of the explanation.

Figure 5b. Grade 2 related explanation, drawing of quantities, written method, and questions for Do-Necessary-Ungrouping-First Method Part II-Continued

As with multidigit addition, the drawings using 5-groupings help students see and explain make-a-ten methods for subtracting like place values within a column. In Step d Doug does 13 - 5 (thirteen minus five) by taking the 5 from the ten ten-sticks leaving 8 ten-sticks ( 5 and 3 make 8). Similarly, the 9 ones are taken from the ten ones circles leaving one circle to get added to the 6 ones in 16 . Such methods are easier in East Asian languages where 13 - 5 is said "ten three minus five" so the ten from which the bottom number can be taken is explicitly mentioned. Some East Asian textbooks have written methods (see Figure 6) that show the ten in the ungrouped top number or assume there is a ten and just show the ones part of the teen number because that is what varies [3]. Such methods might be particularly helpful to less-advanced students in those countries. Lee [29] found that low-achieving Taiwanese students could do subtraction make-a-ten methods better than addition make-a-ten methods but high-achieving students were equally good at both. Lee pointed out that the ten is said and is visible for subtraction: 14 in $14-8$ is said as ten four and students can see the 1 in 14 and take 8 from that ten. Also finding the answer involves adding 2 and the 4 they can see. In contrast, for $8+6$ students have no visual or auditory reminder of the ten and also there is no visual support for finding the answer after they break apart the 6 to be 2 added to the 8 to make ten and the 4 that must be put with that ten. 
Writing the Ungrouped Ten

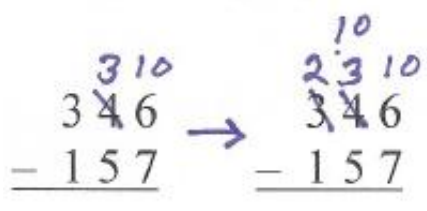

Writing the New Group or a Dot

to Show that $\mathrm{N}$ is One Less

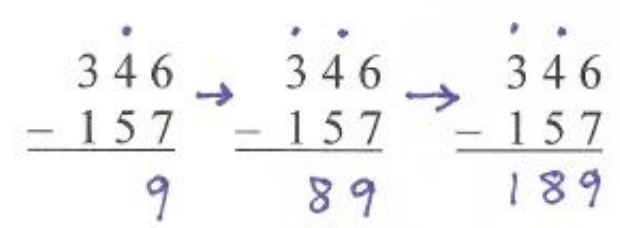

Figure 6. Methods in East Asian textbooks that show the 10 or assume the 10 .

The frequent top-from-bottom subtraction error noted above has been very frequent in the United States, partly because of the usual practice before the Common Core State Standards of introducing problems with no ungrouping (e.g., $78-43$ ) in Grade 1 and only moving to ungrouping problems a year later, in Grade 2, after students had already solidified a subtraction method that seemed to work well: look at a column and subtract the two numbers you see there regardless of their relative size. To address this issue, no general 2-digit subtraction methods (with or without ungrouping) are included in the Grade 1 Common Core State Standards. Therefore, in grade 2, subtraction with ungrouping can be addressed first so students learn to check from the beginning to see if they need to ungroup each column. This initial understanding of subtracting as possibly needing ungrouping, combined with reduced use of the alternating method, may greatly increase understanding of subtraction methods and contribute to a greater number of correct answers. We have seen this effect in Math Expressions classrooms. We also found that carrying out two ungroupings was difficult for second graders if they did this first for general problems such as $832-467$, but that it was much easier for totals within 200 such as $132-67$. Our students moved from 2-digit subtraction to problems subtracting from 200 such as $200-67$ so that they saw immediately that they needed to ungroup one hundred to get ten tens and ungroup one ten to get ten ones (or ungroup 1 hundred to get nine tens and ten ones). They then moved to problems with totals within 200 with one or two ungroupings. Then the step to general problems with larger hundreds such as 832 - 467 was relatively easy.

\subsection{Multidigit Multiplication and Division}

Accessible and mathematically-desirable methods for multiplication and division are shown in Figure 7 along with the array/area models recommended in the Common Core State Standards and used in our earlier research to support understanding and explaining the written methods. As discussed in Steps 2 and 3 above, students first work with arrays of dots or with contiguous unit squares forming a rectangle to make an area model for single-digit numbers and later for multidigit numbers. Students then make sketches like those shown in Figure 7 in which the numbers refer to dots (or other things composing the array) for an array model and to unit squares for the area model.

The Expanded Notation Method in Figure 7 shows helping steps in blue developed by a Grade 4 class in a high-poverty urban school. Students said that these steps would help all of them understand what they were doing in each step, and they wanted to start multiplying to get the largest partial product first so they could correctly align the other smaller partial products under this product. They dropped the steps when they no longer needed them, yielding the common partial products method. But we found in the Step 3 research that even the helping steps Expanded Notation Method was too spatially challenging for some students. They could understand that they were multiplying the tens and the ones in one factor times the tens and the ones in the other factor. But they found it much easier to write these products inside the relevant rectangles in the array/area model and then just add these outside the model as in the Place Value Sections Method in Figure 7. Users of the Expanded Notation Method initially made the Area Model sketches and stopped making them when they no longer needed them.

These two methods meet all of the criteria in Table 1. They both are accessible and mathematically desirable general standard algorithms. The blue helping steps need to be dropped for fluency, but it is better for students to keep using them as long as they are needed because they do not add much time to the method.

The 1-Row Method shown on the top right of Figure 7 is a current common method some people in the United States think is "the standard algorithm." The 1-Row Method is more difficult than the other methods in Figure 7 because it alternates multiplying and adding steps, and it moves from the right while the area model is done most easily from the left. And this 1-Row Method is misleading conceptually. When multiplying 6 tens times 3 ones, one gets 18 tens. But the 1 in 18 tens, which is actually 1 hundred because 18 tens $=180$, is written above the 4 tens. This method does not meet criteria 1, 3, 4, 5, and 6 in Table 1, and so it is recommended only to discuss this misleading aspect and relate it to the area model for understanding if it comes from a student's home. 
Area Model

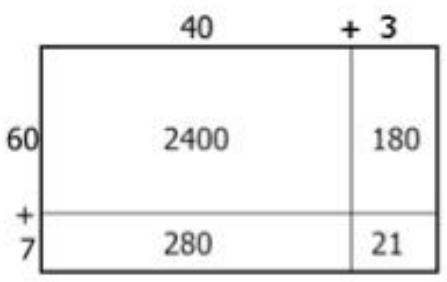

Rectangle Sections

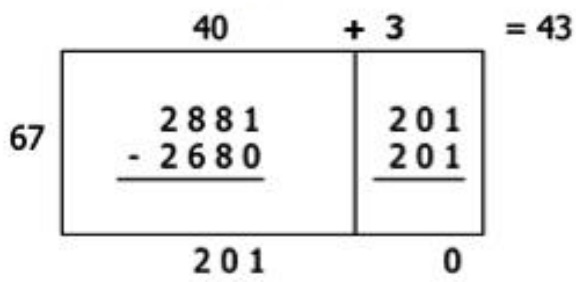

\section{Place Value Sections}

$\begin{array}{r}2400 \\ 180 \\ 280 \\ +\quad 21 \\ \hline 2881\end{array}$

Expanded Notation

$$
\begin{aligned}
43 & =40+3 \\
\times 67 & =60+7 \\
60 \times 40 & =2400 \\
60 \times 3 & =180 \\
7 \times 40 & =280 \\
7 \times 3 & =\begin{array}{r}
21 \\
2881
\end{array}
\end{aligned}
$$

\section{1-Row}

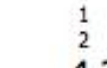

43

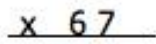

301

258

2881
Expanded Notation

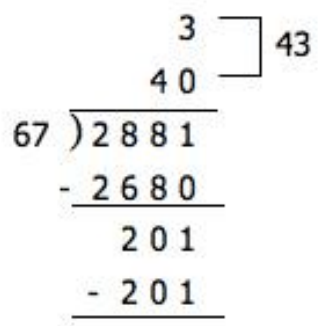

Digit by Digit

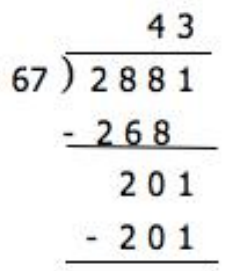

Figure 7. Accessible and generalizable multiplication and division methods.

Fuson and Beckmann [25] show other ways to write the new groups in the 1-Row Method including below in the rows as in the New Groups Below multidigit addition method (see Figure 8). This variation allows students to write products in the correct places and enables them to see the single-digit products in their correct places: 6 ones $\mathrm{x} 4$ ones $=24$ ones, 6 ones $\times 9$ tens $=54$ tens, 3 tens $\times 4$ ones $=12$ tens, 3 tens $\times 9$ tens $=27$ hundreds. This method also provides coherence between the best addition and a good multidigit method. The 2 thousands and 1 hundred are enclosed in a rectangle in Figure 8 to emphasize that they are in the correct columns, which would not be the case if they were written above the problem as in the 1-Row Method.

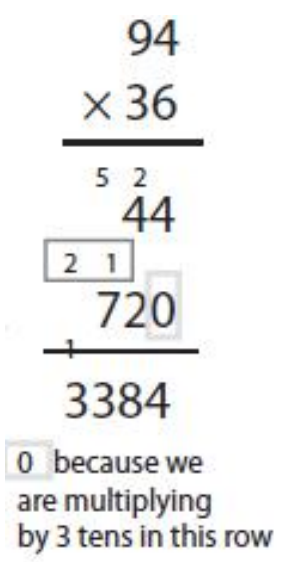

Figure 8. Writing the new groups below to see the single-digit products in the correct columns

Division standard algorithms build up partial products of the known factor to find how many such partial products fit within the dividend (the known product). The known factor (here in Figure 7, 67) is used as the whole side of the array/area model, and the unknown factor is built up along the top (40 and then 3 ). In the Rectangle Sections Method students write the dividend inside the first section (here, 2881), then find the first partial product by multiplying $40 \times 67=2680$, write this partial product 2680 under the dividend 2881, and then subtract to get 201 that still needs to be used in the array/area model. So this remaining 201 is written inside the next partial products area section. Students estimate that $367 \mathrm{~s}$ will fit into 201, multiply $3 \times 67=201$, write that partial product inside the second area section, and subtract it to see that 0 units remain to be used in the area model. The parts of the unknown factor that make the rectangle with an area of 2881 are then added: $40+3=43$.

These same steps can be recorded in the multidigit division format used in the United States, as shown in the Expanded Notation Method in Figure 7. This method shows the values of all of the quantities and so supports initial understanding when related to an array/area model. The Digit by Digit Method only records single digits, so it can be more difficult to understand. This method is explained in Fuson and Beckmann [25] using conceptual place-value language.

Multidigit division can be difficult if students feel they have to write the exact multiplier at each place value. Fuson and Beckmann [25] show minor variations in which students can underestimate a multiplier and keep adding on a partial product without erasing work already completed.

\section{Discussion}

The multidigit addition and subtraction methods 
identified in this research as the best methods do generalize easily to very large numbers. The multidigit multiplication and division methods also generalize to larger numbers, but they can become unwieldy for very large numbers. Computing on squared paper can help keep place values aligned and correct. However, many people around the world are questioning the need for multidigit multiplication and division problems larger than those shown here in Figure 7. The problems shown here are big enough for students to understand the mathematical issues involved in multidigit multiplication and division and to generalize these numeric methods to algebraic work with polynomials in later years.

The mathematical approaches of the multidigit whole number adding and subtracting methods described here also apply to the adding and subtracting of decimals. The lines of reasoning for whole number multiplying and dividing also extend to decimal multiplication and division. The extensions of these written methods for whole number computation to decimal computation are discussed in [34,35].

In the United States many programs now support students to discuss different methods because students may develop different methods, and a student may understand one method better than another. But this can be prolonged with students not moving to develop, discuss, and use efficient, accurate, and generalizable methods in the first year that computation is introduced (see the Common Core State Standards critical areas, as discussed above). And discussing too many methods can be confusing and take a lot of class time. Using a Math Talk Community in which students make drawings to explain steps in written methods and their classmates ask questions is vital for making sense of all methods discussed in a class. One can start with student methods and then introduce the accessible and mathematically-desirable methods described here if they do not come from students. These can be introduced as methods a student in the class did last year or in a story scenario as methods done by the characters in the story (e.g., Tony and Maria who own a store). Such methods need to be shared with parents as worked examples or by posting videos on safe school websites of students explaining the method relating each step to a drawing as in Figures 1 and 5. Such videos are powerful in helping parents understand what students can actually learn and do and what the Common Core State Standards or any country's standards can expect as understanding and explaining. In the following year or two these methods will then begin coming from home as families learn and understand them. All methods used in a classroom can be compared to identify how they are alike and different. This helps students understand the big ideas involved in multidigit adding, subtracting, multiplying, and dividing.

The current common methods that are more difficult and may stimulate errors as discussed above may enter the classroom because family members teach them. These more difficult methods need to be linked to drawings of quantities and explained and related to other methods. If methods from home are not discussed and explained in class, students may combine a method from school and a method from home and thus make errors. For example, see Ron for a method of multidigit subtracting widespread in Latin America and coming from student homes that was combined with the multidigit subtracting discussed here to create an incorrect method [36].

\section{Conclusions}

Students and teachers can understand and become able to explain multidigit adding, subtracting, multiplying, and dividing using methods that are more accessible and more mathematically desirable than many methods now taught around the world. Sense-making in ways discussed here can reduce errors and engender understanding by students and by teachers.

\section{Acknowledgments}

Thanks to the teachers, students, and members of the Children's Math Worlds design research team. This research was funded by the National Science Foundation under grants REC-9806020 and ESI-9816320.

\section{REFERENCES}

[1] M. Beishuizen, K P. E. Gravemeijer, \& E. C. D. M. van Lieshout (Eds.), The role of contexts and models in the development of mathematical strategies and procedures (pp. 163-198). Utretcht, Netherlands: Freudenthal Institute, 1997.

[2] K. C. Fuson \& Y. Kwon, Korean children's understanding of multidigit addition and subtraction. Child Development, 63, 491-506, 1992.

[3] K. C. Fuson \& Y. Li, Cross-cultural issues in linguistic, quantitative, and computational supports for mathematical thinking. ZDM - The International Journal on Mathematics Education, 41, 793-808, 2009. DOI 10.1007/s11858-009-0183-7

[4] K. C. Fuson, D. Wearne, J. Hiebert, H. Murray, P. Human, A. Olivier, T. Carpenter, \& E. Fennema, Children's conceptual structures for multidigit numbers and methods of multidigit addition and subtraction. Journal for Research in Mathematics Education, 28, 130-162, 1997.

[5] J. Kilpatrick, J. Swafford, \& B. Findell, Eds., Adding it up: Helping children learn mathematics. National Academy Press, Washington, DC, 2001.

[6] L. Ma, Knowing and teaching elementary mathematics: Teachers' understanding of fundamental mathematics in 
China and the United States. Mahwah, NJ. Lawrence Erlbaum Associates, 1999.

[7] K. Menninger. Number words and number symbols ( $\mathrm{P}$. Broneer, Trans.). Cambridge: MIT Press, 1969. (Original work published 1958).

[8] K. C. Fuson, Avoiding misinterpretations of Piaget and Vygotsky: Mathematical teaching without learning, learning without teaching, or helpful learning-path teaching?

Cognitive Development, 24(4), 343-361, 2009. doi: 10.1016/j.cogdev.2009.09.009

[9] K. C. Fuson, A. Murata, \& D. Abrahamson. Using learning path research to balance mathematics education: Teaching/learning for understanding and fluency. In R. Cohen Kadosh \& A. Dowker (Eds.), Oxford handbook of numerical cognition (pp. 1036-1054). Oxford, UK: Oxford University Press, 2015. doi: 10.1093/oxfordhb/9780199642342.013.003

[10] In http://www.karenfusonmath.com click on MENU then Publications.

[11] K. C. Fuson \& B. H. Burghardt, Multi-digit addition and subtraction methods invented in small groups and teacher support of problem solving and reflection. In A. Baroody \& A. Dowker (Eds.) The development of arithmetic concepts and skills: Constructing adaptive expertise (pp. 267-304). Hillsdale, NJ: Erlbaum, 2003.

[12] K. C. Fuson \& S. T. Smith, S. T., Complexities in learning two-digit subtraction: A case study of tutored learning. Mathematical Cognition, 1, 165-213, 1995.

[13] K. C. Fuson, S. T. Smith \& A. Lo Cicero, Supporting Latino first graders' ten-structured thinking in urban classrooms. Journal for Research in Mathematics Education, 28, 738-766, 1997.

[14] In http://www.karenfusonmath.com click on MENU then Classroom Videos click on 2 Grade 2 Multidigit Subtraction and G Place Value and Multidigit Addition and Subtraction.

[15] A. Izsák \& K. C. Fuson, Students' understanding and use of multiple representations while learning two-digit multiplication. In M. L. Fernandez (Ed.), Proceedings of the Twenty-Second Annual Meeting of the North American Chapter of the International Group for the Psychology of Mathematics Education, Vol. 2 (pp. 714-721). Columbus, $\mathrm{OH}$ : ERIC Clearinghouse for Science, Mathematics, and Environmental Education, 2000.

[16] A. Izsak, Teaching and learning two-digit multiplication: Coordinating analyses of classroom practices and individual student learning. Mathematical Thinking and Learning, 6(1), 37-79, 2004.

[17] A. Izsák, Learning multi-digit multiplication by modeling rectangles. In R. Speiser, C. Maher, \& C. Walter (Eds., 2001), Proceedings of the 23rd Annual Meeting of the North American Chapter of the International Group for the Psychology of Mathematics Education. Vol. 1 (pp. 187-194). Columbus, OH: ERIC Clearinghouse for Science, Mathematics, and Environmental Education, 2001.

[18] A. Izsák. "You have to count the squares": Applying knowledge in pieces to learning rectangular area. Journal of the Learning Sciences, 14(3), 361-403, 2005.

[19] K. C. Fuson. Math Expressions, Grade 3. Houghton Mifflin Harcourt, Boston, MA, 2006, 2009, 2013, 2018.

[20] K. C. Fuson, Developing mathematical power in whole number operations. In J. Kilpatrick, W. G. Martin, \& D. Schifter (Eds.), A research companion to principles and standards for school mathematics_(pp. 68-94). Reston, Va: National Council of Teachers of Mathematics, 2003.

[21] K. C. Fuson, Toward computational fluency in multidigit multiplication and division. Teaching Children Mathematics, 9(6), 300-305, 2003.

[22] In http://www.karenfusonmath.com click on MENU then Teaching Progressions then Math Expressions and Operations and Algebraic Thinking (OA) Parts 2 and 3 and Math Expressions and Numbers Base Ten (NBT) Parts 2 and 3 .

[23] K. C. Fuson. Math Expressions, Kindergarten through Grade 6. Houghton Mifflin Harcourt, Boston, MA, 2006, 2009, 2013, 2018.

[24] National Governors Association Center for Best Practices, Council of Chief State School Officers, The Common Core State Standards Math. Washington, D.C.: Author, 2010.

[25] K. C. Fuson \& S. Beckmann, Standard algorithms in the Common Core State Standards. National Council of Supervisors of Mathematics Journal of Mathematics Education Leadership, 14 (2), 14-30, Fall/Winter, 2012-2013. Also athttp://www.mathedleadership.org/docs/resources/journal s/NCSMJournal_ST_Algorithms_Fuson_Beckmann.pdf

[26] K. C. Fuson \& Y. Li, Learning paths and learning supports for conceptual addition and subtraction in the US Common Core State Standards and in the Chinese Standards. In Y. Li \& G. Lappan (Eds.), Mathematics Curriculum in School Education (pp. 541-558). Dordrecht, Germany: Springer, 2014.

[27] K. C. Fuson \& Y. Kwon, Korean children's single-digit addition and subtraction: Numbers structured by ten. Journal for Research in Mathematics Education, 23, 148-165, 1992.

[28] K. C. Fuson \& Y. Kwon, Learning addition and subtraction: Effects of number words and other cultural tools. In J. Bideaud \& C. Meljac (Eds.), Pathways to number (283-306), 1992. Hillsdale, NJ: Lawrence Erlbaum Associates. [This is a book of invited chapters celebrating the fiftieth anniversary of the publication of Piaget's book on number. Published in French in Les chemins du nombre (pp. 351-374). Villeneuve d'Ascq, France: Presses Universitaires de Lille.]

[29] Hf Lee, Supports for learning multi-digit addition and subtraction: A study of Taiwanese second-grade low-math achievers. In M. L. Fernandez (Ed.), Proceedings of the Twenty-Second Annual Meeting of the North American Chapter of the International Group for the Psychology of Mathematics Education, Vol. 2 (pp. 723-728). Columbus, $\mathrm{OH}$ : ERIC Clearinghouse for Science, Mathematics, and Environmental Education, 2000.

[30] A. Murata \& K. C. Fuson, Learning paths to 5- and 
10-structured understanding of quantity: Addition and subtraction solution strategies of Japanese children. In R. Speiser, C. S. Maher, \& C. Walter (Eds.), Proceedings of the Twenty-Third Annual Meeting of the North American Chapter of the International Group for the Psychology of Mathematics Education, Vol. 2 (pp. 639-646). Columbus, $\mathrm{OH}$ : ERIC Clearinghouse for Science, Mathematics, and Environmental Education, 2001.

[31] A. Murata \& K. C. Fuson, Teaching as assisting individual constructive paths within an interdependent class learning zone: Japanese first graders learning to add using ten. Journal for Research in Mathematics Education, 37 (5), 421-456, 2006.

[32] K. C. Fuson, Research on whole number addition and subtraction. In D. Grouws (Ed.), Handbook of research on mathematics teaching and learning (pp. 243-275). New York: Macmillan, 1992.

[33] In http://www.karenfusonmath.com click on MENU then Teaching Progressions then Math Expressions and Operations and Algebraic Thinking (OA) Part 2 and Classroom Videos D Kindergarten Parts 4, 5, 6, 7, 8.

[34] In http://www.karenfusonmath.com click on MENU then Teaching Progressions then Math Expressions and Numbers Base Ten Parts 4, 5, 6, 7 .

[35] S. Beckmann \& K. C. Fuson, Meaningful approaches to algorithms for decimals. Presented at the Annual Conference of the National Council of Teachers of Mathematics, New Orleans, LA, April, 2014. This can be found at http://www.karenfusonmath.com click on MENU then Visual Presentations.

[36] P. Ron, My family taught me this way. 1n L. J. Morrow (Ed.), Teaching and learning algorithms in school mathematics (pp. 115-119). Reston, VA: National Council of Teachers of Mathematics, 1998. 